\title{
Research on College Humanistic Care Education Under Modern Education Management
}

\begin{abstract}
Shan Ye
China Metrology University, Hangzhou, China

*Corresponding author. Email: 651698061@qq.com

ABSTRACT

The article firstly points out the modern meaning and purpose of humanistic care: it is to educate adults. At present, the main problems in college education are that college education managers are not born in pedagogy. College managers attach too much importance to rigid system management. Secondly, many methods are put forward to solve the problems of the lack of modern university humanistic care education through the university staff, college students and university environmental publicity. Firstly, college staff shall have their dedication, strengthen their humanities quality and promote the enthusiasm of students from the spirit level of humanistic quality, self-shaping, teaching students and harmonious mode. Universities shall strengthen the publicity measures of campus humanistic care. Finally, it is concluded that the college humanistic education shall be people-oriented. All the school teachers and students are the main educational subjects of humanistic care. The article points out the significance of modern humanistic care education. They are very feasible and practical for the specific measures proposed above. However, it needs the cooperation of college leaders, staff and students, and implementation layer by layer, which can finally achieve the goal of humanistic care education in colleges and universities.
\end{abstract}

Keywords: Modern education, Management, Universities, Humanistic care education.

\section{MODERN PURPOSE OF HUMANISTIC CARE EDUCATION IN UNIVERSITIES}

\subsection{Meaning of "Humanistic Care"}

The concept of "humanistic care" originated in the humanism proposed during the Western Renaissance[1]The main thought is to affirm the value of human nature and human beings, advocate everyone equality, the pursuit of personality liberation, and maintain the dignity of human nature. Modern meaning has two aspects, student level mainly refers to the personality differences and needs, provide, adopt different modes and methods, learning initiative, enthusiasm and creativity to better promote the overall development of college students. The teacher level, modern people have realized that higher education should not only teach knowledge to students, but also pay attention to cultivate their creative spirit, independent spirit, to form the correct values, world outlook and outlook on life. The realization of this goal requires universities to create a good campus environment and atmosphere, so that students can grow up healthily in an environment full of humanistic care.
College educators should be people-oriented, all for the students, and establish a student as the main management system.

\subsection{The Purpose of the Modern "Humanistic Care" of Education}

There are "people" in the heart, educating people into "people", is the action purpose of the humanistic care mode. It is mainly realized through hard work. First, humanistic care is an important demand for today's social development. At present, the exchanges between countries are becoming increasingly frequent and deep in terms of culture, politics and education, and the cooperation between countries is constantly developing towards a multicultural direction. Under this situation of multicultural influence, the influence of individualism and nationalism on the management of universities has reached an unprecedented height. College students' consciousness and mentality have also changed, and some college students began to doubt the scientific nature and practicality of Marxism. These international environmental changes impact the college education system. Secondly, college education reform 
has become the voice of The Times, and the development of The Times makes education reform urgent. However, college educators are used to the traditional education mode in the process of educational practice, and still adopt "indoctrination" methods for teaching. The fixed assessment mode and a single teaching method restrict the personalized cultivation of students, which is inconsistent with the current social needs. Thirdly, the implementation of humanistic care is the practical demand and way for college students to realize their own internal development. Humanistic care recognizes that man itself is the purpose, and the fundamental purpose is the care for human nature, and the respect and love for the existence of life. The core is to affirm the value of human nature and people, which means the yearning, pursuit and transcendence of human life, meaning, value, and purpose. Respect, develop and perfect people is the starting point and the highest purpose of realizing the development of the relationship between teachers-students in colleges and universities. Finally, the psychological problems of college students in modern college education also need to be assisted and solved by humanistic care education.[5]The superior family education environment and the comfortable growth environment make college students have poor ability to resist frustration. In the face of complex college life and social circle construction, college students are easy to lose themselves and produce many psychological problems. When college students enter the society, they will also not adapt to employment. Due to their poor selfcognitive ability, they are easy to feel inferior and confused. Many factors lead to the frequent occurrence of more serious psychological and extreme malignant events in modern college students.

\section{LACK OF HUMANISTIC CARE AND EDUCATION IN COLLEGES AND UNIVERSITIES}

\subsection{Non-Educational Majors for College Education Managers}

Modern college education management is not from education management major, but is engaged in cultivating human work content education career, to shape training work, must systematically learn education theory and management knowledge, master the law of education and management, in the process of practice teaching to constantly improve their political quality, moral quality, and humanistic quality and physical and mental quality. Universities should encourage teachers to actively participate in various training activities to improve teaching quality, broaden professional knowledge and improve teaching methods.

\subsection{Attach too Much Importance to Institutional Management for College Managers [11]}

College managers attach great importance to system management and blindly restrain the teachers and students. Because the system is dead, but the management environment is changeable, and the situation of teachers and students is also complex and changeable. If we only rely on the system for management, people's subjective initiative cannot be fully paid full attention to, and the human change factors cannot be solved in the management process. This has an adverse effect on the education cause of our country.

\section{UNIVERSITIES TO SOLVE THE LACK OF HUMANISTIC CARE EDUCATION}

\subsection{Take University Managers as the Object Solution}

\subsubsection{Advocate the Love and Dedication of Colleges and Universities' Faculty and Staff[2]}

Integrate the humanistic care into the modern college education management. Understand the significance and role of humanistic care in education management. On the one hand, the school leaders respect, view the heart, care for the individual needs of every staff, and understand and support the daily work of every education manager. On the other hand, colleges and universities should actively advocate the love and dedication of the staff. Colleges and universities can through typical demonstration, case education let each staff realize their historical mission and education responsibility, guide the staff in the ordinary work practice love dedication, the pursuit of excellence, in the ordinary life constantly improve their conduct and accomplishment, knowledge and talent, imperceptibly infection and influence every educator. Advocate the love and dedication, and make the dedication become the basic mission and conscious action of every educator.

\subsubsection{Strengthen the Humanistic Quality of the College Staff}

In the process of college education management, in order to improve the quality of education management through humanistic care, it is necessary to constantly strengthen the study of the staff. College management level and practical ability determine the efficiency of education management, in order to improve the level of education management, we must effectively expand the management education knowledge, psychology knowledge, etc., and constantly strengthen the professional ethics, improve the professional dedication, 
sense of responsibility and enthusiasm, to create a harmonious cultural environment.

\subsubsection{Encourage the Work Enthusiasm of College Teachers and Staff Through the Incentive Mechanism[2]}

Incentive refers to a sense of achievement, other recognition, work itself, responsibility and promotion. Education managers of contemporary colleges and universities are generally faced with lack of incentive and more health care. Many college managers, especially middle-level and grass-roots staff work at ordinary times, busy but can not see their own work results, can not feel their sense of achievement, can not get the recognition of leaders and other teachers, and promotion opportunities are slim, for them work is just a means to make a living, not too much value and significance in life. Therefore, colleges and universities should strengthen humanistic care, strengthen the incentive mechanism, and provide more channels for educators to promote vocational and professional titles. And give with them more respect and recognition. Let them see the hope of career development, to realize the work value, life goals, in order to fully mobilize the work enthusiasm and initiative of the faculty and staff.

\subsubsection{Take Safeguarding the Interests of Students as the Starting Point of Humanistic Care for College Staff[2]}

The people-oriented education manager is to take people as the management and foundation of colleges and universities. Protecting students' interests serves as the starting point of humanistic care. Relying on the majority of educators, through scientific management means, perfect management system and flexible schoolrunning mechanism, so that education management can produce a good economic benefit and social effect. While implementing scientific management, universities should also pay attention to humanistic care, because the system is dead and people are alive, they need to rely on the active participation of people and flexibly adjust the system according to their subjective initiative. To mobilize people's enthusiasm, give full play to the subjective initiative cannot be separated from humanistic care, the rigid rights management mode will only bring people boredom. Therefore, on the basis of scientific management, the college education management also needs to integrate into the humanistic care, further improve the education management function, and realize the education management culture.

\subsubsection{Care about Students from the Spiritual Level for College students}

The core of humanistic care literacy is that college educators care about students from the spiritual level and provide psychological counseling to students. When teachers get along with students, they should be good at listening to students' ideas, pay attention to the psychological changes of students, put themselves in the sake of students, and establish a harmonious and equal relationship between teachers and students. Colleges and universities should inspect teachers strictly and regularly to urge teachers to constantly improve their thoughts, culture and moral quality, and integrate humanistic care into teachers' educational concepts. Therefore, improving the humanistic quality of teachers and fully mobilizing the subjective initiative of teachers are the cornerstone of ensuring the development of humanistic care education work and the realization of humanistic education.

\subsection{Solution Method with College Students as the Object}

\subsubsection{Cultivate the Humanistic Quality of College Students}

Humanistic education can cultivate students to form a good mental outlook, but also can improve students' moral cultivation. However, under the exam-oriented education, many students must accept the examination pressure and entrance pressure from an early age, learn passively under the guidance of textbooks and teachers every day, and lack the learning of humanistic knowledge. Therefore, in order to realize humanistic education and build a civilized campus, universities must pay attention to the cultivation of students' humanistic quality and provide students with more learning opportunities that can improve their humanistic quality. Only by raising the humanistic education of college students to the height of professional education and promoting the integration of professional education and general education, can the humanistic education receive practical results. For example, it is necessary to pay attention to the setting of humanities courses in the professional education system, strengthen the penetration of arts and sciences, and the humanities courses connected with majors must account for an appropriate proportion, and be guaranteed in the mechanism, so as to realize the scientific investment of people and property. Hold colorful cultural activities. For example, each college can regularly carry out classic cultural reading reading activities, or hire outstanding teachers to give lectures to let students understand the traditional Chinese and foreign cultural classics, so as to cultivate the humanistic spirit of college students. By holding a series of cultural activities, enabling students can actively participate in it, 
promoting cultural knowledge is constantly internalized into the college students' own humanistic quality.

\subsubsection{Self-shaping for College Students}

College teachers should also guide college students to actively "shape themselves". Any education is bidirectional, and no matter how people identify the subject of education, they must recognize the important role of educators themselves. Humanistic literacy education is also a process of external causes playing through internal causes. The mobilization of college students' own initiative is always the key to the improvement of their humanistic quality. If college students themselves have the goal of growing into an all-round development of talents, and have a good learning attitude and basic learning ability, then the external environment and the education platform and the literacy education improvement system can play an important role. Otherwise, anything external is just a decoration that cannot work. Therefore, guiding college students to actively shape themselves is an important link of college students' humanistic quality education.

\subsubsection{Humanistic Care Education According to Their Aptitude}

In the process of college education, every student is an independent individual, and every student has different differences, but also has different hobbies and pursuits. In such an environment, the students should be condensed into a whole. In the process of education, students are the main body of education and management. In the management of college education management, to penetrate humanistic care, it is necessary to strengthen humanistic care education for students. Take methods, such as choosing students 'class students with high comprehensive quality as class cadres; effectively organize students to participate in collective activities, and constantly strengthen students' love for the collective. Teachers not only pay attention to students 'professional knowledge, but also pay attention to students' ideology, to carry out various targeted spiritual and cultural activities, to create a good development platform for students. Teachers should respect the students 'personal personality, understand each student's ideology, and constantly strengthen the communication with the students, always adhere to the people-oriented, thought-oriented.

\subsubsection{Innovate the Teacher-student Interaction Mode[3]}

Colleges and universities should reform the traditional management system. Enhance the friendship between teachers and students through campus activities, and form a learning state of mutual assistance between teachers and students. Enhance the friendship between students, enhance the feelings between students, encounter problems in learning to solve through discussion. Teachers regularly organize campus activities with students as the main body, and penetrate the concept of humanistic care to students through the activities. Students through participating in activities can coordinate study and pressure in daily life to promote the healthy development of students' personality. Teachers should play the guiding role of humanistic ideology, pass on positive energy to students, set an example, and give students correct guidance. We should also pay attention to students 'learning and growth during school, understand students' problems and further solve them.

\subsection{Take the College Cultural Environment as the Object Solution}

\subsubsection{University Campus Publicity Angle}

Universities build elegant university cultural environment and culture. While strengthening the construction of material culture, the "soft power construction" of campus culture should be strengthened, so that college students can be influenced and influenced imperceptibly, and then improve their humanistic quality. Humanistic care publicity methods include, such as placing handicrafts in the publicity column on the school, setting up a green learning environment in the classroom, and using various ways to create a good humanistic campus environment for the whole school teachers and students. Carry out various training of humanistic care or benign competition activities, strengthen the effective publicity of humanistic care, let humanistic care penetrate into all aspects of colleges and universities, and effectively improve the education management level of modern colleges and universities.

\section{CONCLUSIONS}

The humanistic care of college education management shall not be aimed at students. All teachers and students respect the main position of all. Only by putting forward people oriented, constantly exploring and innovating and seeking more reasonable education management methods, we can promote the development of modern university education.

Education must cultivate people's self-determination ability, rather than cultivate people to adapt to the traditional world. Education does not focus on practical, and teach knowledge and skills in order to awaken the power of students, cultivate their self-initiative, abstract induction and understanding, so that they can make a meaningful choice in the unpredictable future situation. Scientific education is a key link to promote the development of market economy. Scientific education in colleges and universities has brought a large number of 
professional talents and innovative talents into the market, to promote the modernization and development of important areas of the country. However, humanistic education is of greater significance to the long-term development of people and society. Humanistic education can purify college students' skills and individualism, cultivate sentiment, strengthen conduct, enhance morality, promote the all-round development of college students, and deliver a large number of political talents who can serve for the people and the motherland. Between two, humanistic care education is the foundation and the purpose. Only when scientific education reflects more humanistic care education, it is more conducive to personal development, school development, social development and the long-term development of human civilization.

\section{REFERENCES}

[1] Zuo Yang. Analyzing the Modern College Education Management under the humanistic care [J]. Scientific and scientific Chinese people. 2016, (30): 117 .

[2] Liu Peizhang. Light Humanistic Care in Modern College Education Management [J]. Employment and security. 2018, (23):16-17.

[3] Bin Huang Yu. Difficulties and Discussion of Humanities Education in University of Science and Technology [J]. College education. 2018, (10):132134.

[4] Xie Ronghua. Research on Modern College Education Management Based on Human Care [J]. Curriculum Education Studies. 2018, (5):25.

[5] Yue Feng. Analysis on the Innovation of Modern College Education Management from the View of Humanistic Care [J]. Journal of Hubei Correspondence University. 2018, 31(15):1-2.

[6] Lin Yi. The penetration of humanistic care in the College Education Management [J]. Contemporary teaching and research theory cluster. 2018, (5):88, 90 .

[7] Lei Xinye, Zhang Xuechuan. Research on College Education Management Based on the perspective of humanistic care $[\mathrm{J}]$. Study of the propagation force. 2020, (17):142-143.

[8] Xue Fengfeng. Modern College Education Management under the perspective of humanistic care [J]. Curriculum Education Studies. 2019, (44):20-21.

[9] Wang Wendi. Study on Humanistic Care in College Student Education Management [J]. Young people. 2019, (48):57.
[10] Zhang Chunping, Ding Mingyue. Modern College Education Management under the perspective of humanistic care $[\mathrm{J}]$. Science, Education and Literature (journal). 2019, (8):7-8.

[11] Tang Jie. An Analysis on Modern College Education Management from the View of Humanistic Care [J]. Changjiang Cong. 2021, (4):115-116.

[12] Sun Shijie. Research on College Education Management Based on the perspective of humanistic care $[\mathrm{J}]$. Education and teaching Forum. 2020, (52):21-22.

[13] Wang Daojun, Guo Wen'an. Education [M]. The People's Education Press. June, 2016.

[14] Chen Qi. Educational Psychology [M]. Higher Education Press. February 2020.

[15] More than Wednesday. Management, [M]. Higher Education Press. March, 2018. 